\title{
The Artistic Scene of Richard Prince
}

\author{
Binwen Zeng \\ Southwest University, Chongqing 400715, China \\ Email: cheerfans@yeah.net
}

\begin{abstract}
Richard Prince is an important artist born in the 1950s. His re-photography works are quite controversial. However, as for Richard Prince, re-photography is just the way to practice his works of art although these art works are often labeled as "photography" in that time. Indeed, it is necessary for him to accomplish his art works by using re-photography (a pure skill) rather than intentionally completing a photographic work. From the perspective of social and cultural criticism, Prince's works are not so obscure and rebellious. His art works are mainly concerned with media, advertising and personal identity in the modern society. A series of controversies around Prince reflect the conflict of different tastes between the masses and the elite.
\end{abstract}

Keywords: Richard Prince, re-photograph, post-modernism

\section{Introduction}

Richard Prince has been selected as one of the "Power 100" of Art Review, a British magazine, for three times. Since the end of 1970s, he has been involved in artistic creation related to many fields such as photography, sculpture, painting, installation, and so on. His works have been successively collected by many important institutions like Metropolitan Museum of Art, Solomon R.Guggenheim, Whitney Museum of American Art, Modern Art Museum of Fort Worth, etc.

Prince is also extremely popular in the art market. His series of Untitled (Cowboy) broke the auction records of photographic works two times in 2005 and 2007. However, he still failed to satisfy everyone. Due to his appropriation of large numbers of ready-made pictures in his own works, he was criticized by many magazines and newspapers. Once, Prince described the process of his artistic creation in his diary, "load the camera with film and fix it on a tripod, then place (the selected) picture in front of the lens. At last, just press the shutter." ${ }^{,[1]}$ According to him, the photo he produced in that way was his final work. He named it as "re-photography". This extremely easy way of creation has left Prince in deep dispute.

\section{Dispute out of a lawsuit}

The main criticism came from the mass media. They could not understand why the "stolen" pictures could become so priceless, which led to a comprehensive judgement on "appropriation art". The Telegraph criticized that Prince "robbed" the American legend - cowboy image, from one of the Marlboro advertisements. ${ }^{[2]}$ At the same time, in contrast, many institutions such as Whitney Museum of American Art, Metropolitan Museum of Art and Solomon R.Guggenheim held high-level personal exhibitions for Prince. The two different attitudes reflected the difference between the mass culture represented (or guided) by mass media and the elite taste popular in the art circle. However, what was funny was that, Prince proposed his idea of "questioning authority" as a public, and the targets he questioned were just the elites who were in charge of the "authority". From the final results, Prince's works were in turn accepted by the elite class he questioned and rebelled, but were refused by the public (the main audience of the mass media). If we regard Prince's art as a seed with the spirit of criticism and innovation, we can say this seed was born in the public position, but is growing in the elite position. And till now, its influence and inspiration are still expending and growing. An obvious sign is that, the legal system has approved and confirmed the "rationality" of Prince's appropriation art.

In 2009, Patrick Cariou, a French photographer, accused Prince of tort. This case got attention from all circles. Prince lost at the first trial but successfully reversed the verdict at the second trial. At the beginning of this case, Prince's appropriation got confirmed already. However, the focus of the debate was how to judge his appropriation was belonging to "fair use" or not. At the first trial, judge Deborah Batts indicated that she could not understand "why it can be considered as a kind of innovation just by collaging an electric guitar and painting two circles with the paint". ${ }^{[3]}$ (See Figure 1) According to her, Prince's work was a plagiarism of Patrick. The Andy Warhol Foundation for the Visual Arts Inc. and Robert Rauschenberg Foundation which had supported Prince before explained, "after divorced from the context of art history, it is very difficult to achieve the knowledge content and aesthetic significance of artworks just through simple viewing."[ 
] In other words, the interpretation of an artwork should be in accordance with its own discourse system, which was deeply agreed by the chief judge B. D. Parker of the second trial. In his opinion, Prince's work was totally different from the original of Patrick. In addition, he accused that the District Court used "wrong viewpoints" during the first trial. In the trial report, Parker wrote, "We have examined the two works separately and carefully, which makes us believe that Prince's work is completely different from Patrick's photograph. ...the unique composition, representation, size, color and media of Prince's work prove how different it is from the original. Through comparison, Prince's work shows its connotation in a better way." ${ }^{[4]}$

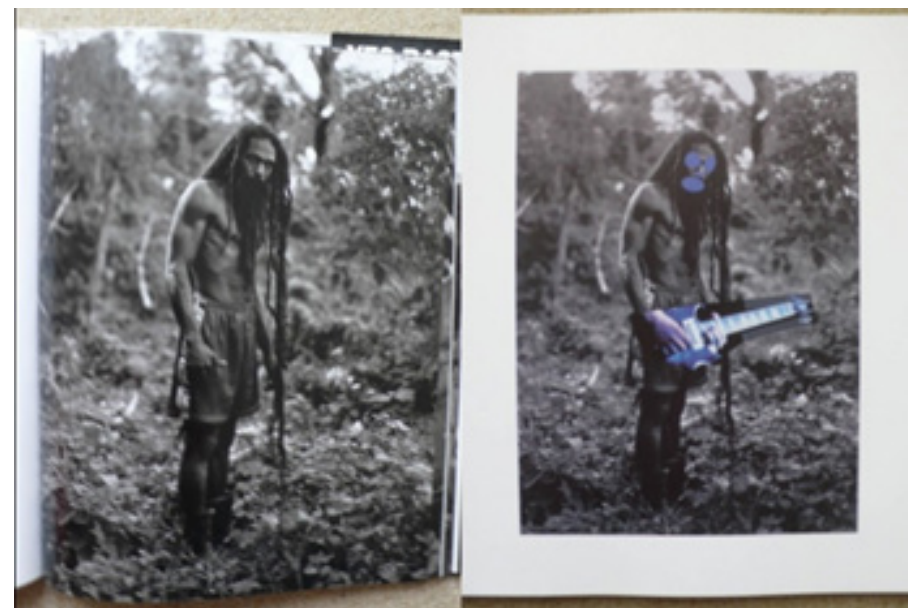

Figure 1. Left: by Patrick Cariou; right: by Richard Prince

Obviously, judge Parker examined Prince's work in an "artistic way", which represented that "artistic way" was approved by the legal discourse. Amy Adler, professor of Art and Law in New York University, made a further analysis. He realized two significant breakthroughs from this case. One is that "the court determines an artwork belongs to "fair use" or not without entirely depending on the comments the artwork received."; the other is that "the personal testimony of the author (Prince) no longer plays a decisive role in the judgement of whether the work changed or not." ${ }^{[5]}$ It means that, "artistic way" becomes a main standard for legal investigation and the judgement of artworks.

"Artistic way", similar to artistic tradition, is a paradigm recognized (or acquiesced) by the art authority. As an important appropriation artist, most of Prince's works are regarded as questioning the traditional photography, and at the same time, as a challenge to the art authority. From the result, we can see that, the art authority accepted the challenge through absorbing. In this way, new "artistic way" is formed and keeps expending its influence.

\section{Theoretical explanation}

Though Prince got the theoretical support and recognition since the beginning, but till now a fair interpretation system has not been formed. The biggest difficulty is that the discourse space of an artwork cannot be fixed, because in different discourse spaces, an artwork has different meanings. Especially when several spaces overlap with each other, it will lead to more complicated changes of the meaning of an artwork. Obviously, the tradition of dividing art into categories is unable to adapt to this kind of changes. Currently, a more common way is to interpret Prince's works with a broad and variable concept.

In 2009, Douglas Eklund planned an exhibition named "The Pictures Generation: 1974-1984" at the Metropolitan Museum of Art. Prince was involved into the narration of this exhibition as one of the invited artists. According to Eklund, during the ten years, the art of photography generally showed "a complete break between the concept photography and the modernist aestheticsy art photography". This concept dropped a hint on the trend of how the educational circle understand the relation between post modernism art and modernism art. According to this trend, post modernism art can be seen as a kind of resistance to modern art, and there is always a rift between the two. Some other scholars, such as James Elkins, promoted that post modernism art is a kind of continuation of the modernism art. Though there are a lot of disputes around this top, the transformation occurred during 1970s to 1980s is obvious.

About this exhibition, Eklund used "Pictuers", a critical term, which was firstly adopted by Douglas Crimp at an exhibition in 1977. Crimp invited five artists: Troy Brauntuch, Jack Goldstein, Sherrie Levine, Robert Longo and Philip Smith. He hoped that this term can not only reflect the main characteristics of these young artists, but also indicate the 
uncertainty of their arts. ${ }^{[6]}$ Two years later, Crimp gave up this term. Instead, he used "post modernism" to summarize the changes of the field of photography during the 1970s. He described Prince's works like this.

In our culture, what we control the most is mass advertising. Its photographing strategy is, as a form of text, to cover how it gets controlled. Richard Prince stole those most ordinary and direct images, and bravely put them in the context of art photography. Through isolating, enlarging, and juxtaposing the fragments of commercial pictures, Prince's work directly shows how the ubiquitous reality lies invade people's lives. ${ }^{[7]}$

In his paper, Crimp did not make a more in-depth discussion about "the invasion of reality lies into life". In 1983, Foucault put forward the concept of "the construction of subjectivity". He believed that the subjectivity, through internalizing the concepts of a rational man into each individual's self-consciousness, makes the standardization shown as the individuality of individual's freedom of choice. This is completely exposed in "Makeup". The idea that "beauty is like a religious order to women" was transformed into the "personalized freedom of choice", which slipped into the selfconsciousness. By means of showing the process of constructing the subject, Prince reveals the fictional truth of the "self". This kind of mighty power looms large in a society centered on the economic structure of global capitalism. Commercial advertising is nothing but a tool to be pushed forward by it.

\section{Re-photography}

In the "re-photography" of Prince, the most controversial originality is not as simple as one might imagine. The common misunderstandings lie in the accusation of "theft" against Prince or the excessive worship to his innovation. Rosalind Krauss once wrote an article on the issue of originality, trying to eliminate the opposite relation between reproducibility and originality through analyzing the works of Manet and Rodin (two artists highly praised by modern art). Their works, which are widely regarded as highly original, also have the problem of duplication and repetition. In Krauss's opinion, in the system of modern aesthetic, "although originality is commendatory, while repeated imitation is derogatory, the two of them are often tied together, interdependent and mutually supportive". ${ }^{[8]}$ According to the most prejudices, "the Gate of the Hell" (although it is a bronze copy) of Rodin is an original work, while the "re-photography" of Prince is a reproduction of the copy (although it is actually shot and developed by the artist himself and finally presented as an "original photo"). However, by means of the rational analysis, viewers are able to find both the reproducibility in the works of Rodin (or Manet) and the originality in the re-photograph works of Prince. Furthermore, the originality, as well as the imitation and reproduction, is not just limited to a certain aesthetic system. Instead, they are a set of universal attributes in the artistic creation. In different discourse spaces, there are a kind of corresponding tendency: modernism flaunts originality and suppress imitativeness, while postmodernism not only advocates reproduction, appropriation and collage, but also "challenges" originality. (See Figure 2)

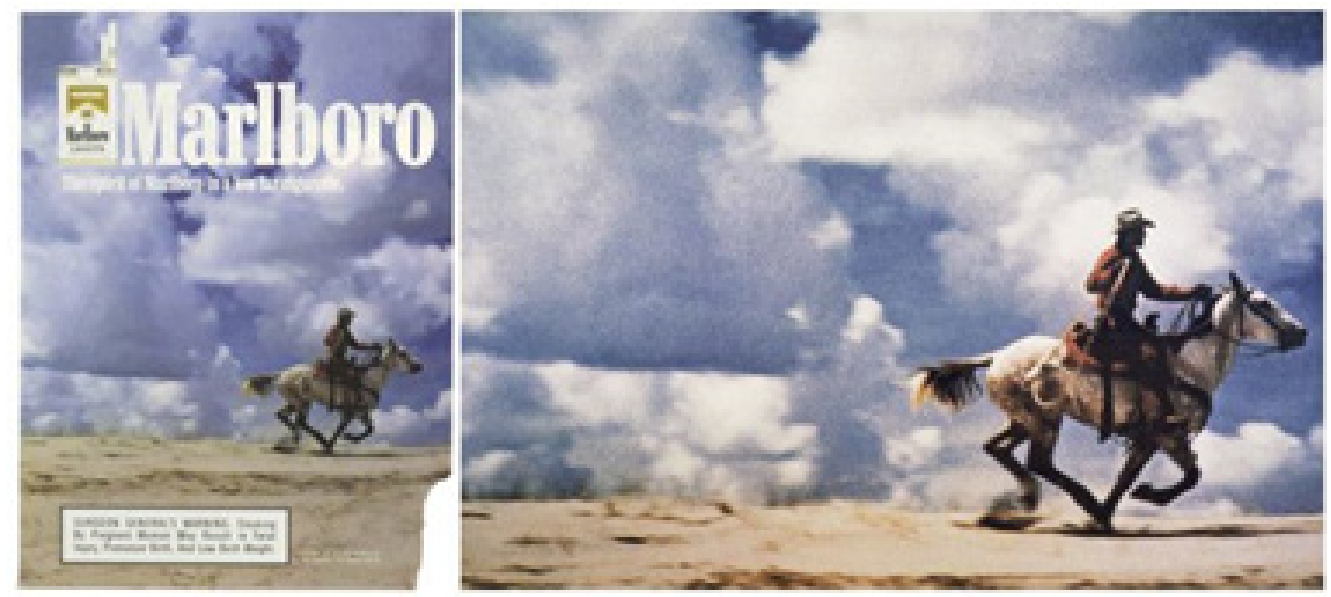

Figure 2. Left: from Malboro; right: by Richard Prince

The word "challenge" here is only used as a term for the occasion and antithesis, because the postmodernist art does not really challenge, or overthrow the originality of modernism. By means of "Allegorical Impulse", Craig Owens legitimized the "appropriation" in the art world. According to him, the postmodernist art is created in an allegorical way." The allegorists never invent the material, but requisition it", which they place in the structure they have designed, thus giving it a new meaning. When artists process images through collaging, clipping and re-photographing, they have already "eliminate not only their echoes and meanings but also their authoritative claims for the meaning". ${ }^{\left[{ }^{[}\right]}$In the new discourse 
space, the representation of the original image is comprehended as the content, which in endowed with new meanings such as reflection, disclosure and even criticism, etc. When Prince's originality was confirmed, the accessibility of "rephotographing" blurs the uniqueness of his works.

Another breakthrough in "re-photographing" is that the subjects shift from the traditional reality to the images. In the process of creation, Prince deliberately removed all the information about the original image as a reality, which makes the viewers unable to realize the environment around it. Without any labels, it is very easy for the viewers to confuse Prince's works with the original images. The traditional photography "recreates the subject in the form of a picture, which is a way of connecting with the subject." ${ }^{[10]}$ Now, the subject, which once was the "object", has been turned into the image. In fact, Levin started shooting the images before Prince. Unlike Prince, on one hand, Levine chose to shoot the photos with the author's signature, while Prince chose the Public Pictures "without any authors". On the other hand, while Levine regarded re-photographing as a kind of tentative experiment, which only lasted for a very short time, Prince uses it as a consistent creating mean. Therefore, we can see that Prince has a more comprehensive understanding about re-photographing. For the final presentation of his works, Prince chooses the traditional "original photograph", which is a tradition since photography became a kind of art.

\section{Conclusion}

Although there is no doubt about the complexity of these works, which are recognized or encoded in a variety of discourse spaces, including the consumer society, subjectivity, postmodernist art, art photography and so on, "purchase", as the most direct way, brings them into the surface of the commercial society. One year after he won his case (the law codified "appropriation"), Prince again challenged the tradition. In December 2014, Prince presented his new works in Gagosian Gallery, which were entirely printed by machines, subverting his previous "original photographs". According to the report, Prince simply used his cellphone to take some screenshots of the pictures on Instagram, and then sent them to his assistant to print them out. Even so, the supporters of Prince still regarded these works as bold originals, and a lot of buyers scrambled for them at a price up $\$ 20,000$ each.

In Buchloh's view, these buyers are very lucky, who adopts the way of purchase to consume the "era in which the subject is undergoing a universal destruction". They "are people who lavishly squander and consume the surplus value of social production. The outstanding performance of art in this respect is just a shadow play of capitalism itself". ${ }^{[1]}$

\section{Reference}

[1] Kristine McKenna, Jonathan Lethern, Richard Prince. Richard Prince: Collected Writings. Hatje Cantz Publishers; 2011.

[2] Richard Dorment. Richard Prince: The Coolest Artist Alive. The Telegraph. 2008-7-15.

[3] Leigh Anne Miller. Judge Rules Against Richard Prince in Appropriation Case. Art in America. 2011-3-22.

[4] Brian Boucher. Warhol and Rauschenberg Foundations Ask to Weigh in on Cariou v. Prince. Art in America. 2013-10-24.

[5] Brian Boucher. Richard Prince Wins Major Victory in Landmark Copyright Suit. Art in America. 2013-4-25.

[6] Douglas Crimp. Pictures. October. 1979; (8): 75.

[7] Douglas Crimp. The Photographic Activity of Postmodernism. October. 1981; (15): 100.

[8] Rosalind Krauss. The Originality of the Avant-Garde: a Postmodernist Repetition. October. 1986; 18: 64-66.

[9] Craig Owens. The Allegorical Impulse: Toward a Theory of Postmodernism. October. 1980; 12: 75.

[10] Micheal Newman. Richard Prince Untitled (Couple). Cambridge, MA, US: The MIT Press; 2006.

[11] Benjamin H. D. Buchloh. Neo-Avantgarde and Culture Industry: Essays on European and American Art from 1955 to 1975. Cambridge, MA, US: The MIT Press; 2014. 